\title{
Long-Term Effects of Comprehensive Inpatient Rehabilitation on Function and Disease Activity in Patients with Chronic Rheumatoid Arthritis and Ankylosing Spondylitis
}

\author{
Kronik Romatoid Artrit ve Ankilozan Spondilitli Hastalarda Kapsamlı Yatan Hasta \\ Rehabilitasyonunun Fonksiyon ve Hastalık Aktivitesi Üzerindeki Uzun Süreli Etkileri
}

\author{
Figen AYHAN, Muharrem GEÇENE, Rukiye GÜNDÜZ, Pınar BORMAN, Rezan YORGANCIOĞLU \\ 1st Departments of Physical Medicine and Rehabilitation, Ankara Training and Research Hospital, Ankara, Turkey
}

\begin{abstract}
Objectives: We compared the inpatient rehabilitation model (IRM), provided by the physiatrist, physical therapist, rehabilitation nurse and clinical psychologist, with the home exercise model (HEM), provided by the physiatrist for the rehabilitation of patients with rheumatoid arthritis (RA) and ankylosing spondylitis (AS).

Patients and methods: One hundred and twenty eligible adult patients [60 RA (mean age 51.8 \pm 11.7 ) and 60 AS (mean age 39.7 \pm 10.4 )] requiring rehabilitation treatment who had not received physical therapy (PT) in the past two years were included in this study. Participants were randomly allocated into two groups IRM or HEM. The primary outcome was one of the following measures from baseline to 15 months: Disease Activity Score of 28 joints (DAS28) and Health Assessment Questionnaire (HAQ) scores for patients with RA and scores of Bath Ankylosing Spondylitis Disease Activity Index (BASDAI) and Bath Ankylosing Spondylitis Functional Index (BASFI) for patients with AS. Outcome assessors were blinded. General estimated marginal means of multivariate comparisons were performed for both "within-subjects" and "between-subjects" for statistical analyses.
\end{abstract}

Results: Mean disease duration of patients with chronic RA and AS were $8.5 \pm 6.4$ (median 7) and 8.7 \pm 7.8 (median 6) years, respectively. Changes of DAS28 and HAQ scores were better in the IRM group than the HEM group. While most of the patients with RA used combined disease-modifying antirheumatic drugs, none of the patients used anti-tumor necrosis factor agents for disease control. BASFI and BASDAI score improvements were not different in both groups. Inpatient rheumatologic rehabilitation programs improved physical function and disease activity in patients with RA and AS. However, statistically significant changes were detected in the DAS28 and HAQ scores of RA patients.

Conclusion: Since patients' functioning is a central aspect of the rheumatic diseases, and remission is rare for these diagnoses, rheumatologic rehabilitation programs should be applied to all of these patients. Inpatient care was useful for patients with RA in contrast to patients with AS. It might be related to more resting periods in inpatient care as opposed to the usual care or ineffective drug therapy for continuing disease process in patients with AS.

Key words: Ankylosing spondylitis; disease activity; function; rehabilitation; rheumatoid arthritis.
Amaç: Romatoid artrit (RA) ve ankilozan spondilit (AS) rehabilitasyonunda fizyatrist, fizyoterapist, rehabilitasyon hemşiresi ve klinik psikolog tarafından uygulanan yatan-hasta rehabilitasyon modeli (YRM) ile fizyatrist tarafından verilen ev-egzersiz modeli (EEM) karşılaştırıldı.

Hastalar ve yöntemler: Rehabilitasyon tedavisi gereken fakat son iki yıldır fizik tedavi almamış 120 seçilmiş yetişkin hasta [60 RA (ort. yaş $51.8 \pm 11.7$ ) ve 60 AS (ort. yaş $39.7 \pm 10.4$ )] çalışmaya dahil edildi. Katılımcılar YRM ve EEM olarak rastgele iki gruba ayrıldı. Primer son-durum başlangıçtan 15-aya kadar aşağıdaki ölçeklerden birisiydi: RA'ı hastalar için 28 eklemlik Hastalık Aktivite Skoru (HAS28) ve Sağlık Değerlendirme Ölçeği (SDÖ) ve AS'li hastalar için Bath Ankilozan Spondilit Hastalık Aktivite Indeksi (BASHAi) ve Bath Ankilozan Spondilit Fonksiyon Indeksi (BASFi). Son-durum değerlendiricileri hastaların ait oldukları gruplardan habersizdi. İstatistiksel analizde aynıhastada ve hastalar arasında uç-tahmin değerler genel tahmini çok-değişkenli karşılaştırmalar yapıldı.

Bulgular: Ortalama hastalık süresi, kronik RA'lı ve AS'li hastalarda sırasıyla $8.5 \pm 6.4$ (median 7) ve 8.7 \pm 7.8 (median 6) yıl idi. HAS28 ve SDÖ skorlarındaki değişim YRM grubunda EEM grubundan daha iyiydi. Hastalığın kontrolü için RA'lı hastaların çoğu kombine hastalık modifiye edici ilaç kullanırken, hiçbir hasta anti-tümör nekroz faktör ajan kullanmiyordu. BASFi and BASHAi skorlarındaki iyileşme gruplar arasında farklı değildi. Yatan-hasta romatolojik rehabilitasyon programları RA ve AS'li hastalarda fiziksel fonksiyon ve hastalık aktivitesini düzeltir. Buna rağmen, RA'lı hastaların HAS28 ve SDÖ skorlarında istatistiksel önemli değişimler saptandı.

Sonuç: Hastanın işlevselliğinin romatizmal hastalıklardaki merkezi yönü ve bu hastalıklarda remisyonun nadir olması nedeniyle romatolojik rehabilitasyon programları tüm hastalara uygulanmalıdır. Romatoid artritli hastalarda AS'li hastaların aksine yatan hasta bakımı faydalı idi. Bu durum AS'li hastalarda yatanhasta bakımındaki daha fazla istirahat süresine veya devam eden hastalık sürecinde etkisiz ilaç tedavisine bağlı olabilir.

Anahtar sözcükler: Ankilozan spondilit; hastalık aktivitesi; fonksiyon; rehabilitasyon; romatoid artrit.

Received: June 6, 2010 Accepted: October 11, 2010

Correspondence: Figen F. Ayhan, M.D. Ankara Eğitim ve Araştırma Hastanesi 1. Fizik Tedavi ve Rehabilitasyon Kliniği, 06340 Ankara, Turkey.

Tel: +90 312 - 5953392 e-mail: figenardic@hotmail.com

Presented at the $17^{\text {h }}$ European Congress. European Society of Physical and Rehabilitation Medicine, May 23-27, 2010 Venice, Italy.

(O2011 Turkish League Against Rheumatism. All rights reserved. 
Rheumatoid arthritis (RA) is a chronic, inflammatory disorder affecting primarily the synovium of small hands and feet joints and characterized by osteodestruction to the cartilage and bone presenting with erosions. Ankylosing spondylitis (AS) is another chronic inflammatory disorder mainly affecting the fibrocartilage of the axial skeleton and peripheral joints and characterized by both osteodestruction and resulting osteoproliferation such as syndesmophytes and ankylosis. Both diseases progress and lead to chronic pain and prominent disability. ${ }^{[1-4]}$

The treatments of RA and AS should be multidisciplinary and include pharmacologic and nonpharmacologic interventions. Rheumatoid arthritis should now be considered as an immunologic emergency in which early and aggressive disease-modifying antirheumatic drugs (DMARDs) intervention is considered for the suppression of disease activity and preservation of articular structure and in turn function. ${ }^{[1]}$ In contrast, nonsteroidal anti-inflammatory drugs (NSAIDs) and tumor necrosis factor (TNF)-blockers are the only effective drugs for the therapy of AS because the traditional DMARDs are not effective, especially for axial disease. Despite these effective pharmacologic treatments, most of the patients have not achieved remission at follow-up. In those patients whose disease activity is not fully controlled, RA and AS can have a significant impact on their physical, emotional and social functioning. Therefore, rehabilitation treatments, such as physical therapy (PT), occupational therapy (OT), and exercises, have played an adjunctive role in the pharmacologic management of RA and AS. Rheumatologic rehabilitation aims to prevent physical impairment and restore functional ability through the use of education, exercise, aids for daily living and mobility, and physical modalities. ${ }^{[3,4]}$

Despite widespread positive clinical experience with rehabilitative interventions, the scientific evidence for their effectiveness is, in general, scanty due to a lack of studies with sufficient methodological quality. There is various data about the impact of different parts of rehabilitation in $\mathrm{RA}^{[2-18]}$ and $\mathrm{AS}^{\left[{ }^{[18-31]}\right.}$ These parts consisted of education, ${ }^{[8,17]}$ manual therapy, ${ }^{[27]}$ exercises, ${ }^{[5,6,12-15,22,25,26,28]} \mathrm{PT},{ }^{[3,16,19]} \mathrm{OT},{ }^{[9,20,24]}$ and whole rehabilitation approaches ${ }^{[7,10,11,23]}$ used in studies. Actually, the whole rheumatologic rehabilitation program, including a combination of education, exercises, PT and OT, is tailored to the patients' individual needs in clinical rheumatology practice despite a limited number of these kinds of studies. Also, the variable quality of the reporting of clinical trials before the CONSORT statement ${ }^{[32]}$ for the standardization of the reporting of clinical trials was published also contributes potential bias in which trials with positive results are more frequently published than negative studies.

The aim of this randomized controlled study was to evaluate the long-term effects of inpatient rehabilitation using composite disease activity measures and functional instruments in patients with RA and AS. For this purpose, we compared the inpatient rehabilitation model (IRM) with the home exercise model (HEM) for treating patients with RA and AS.

\section{PATIENTS AND METHODS}

\section{Participants}

The setting of the trial was a tertiary rheumatologic care center that treats large numbers of patients with inflammatory rheumatic diseases and regularly follows-up 785 charts annually.

The Institutional Review Board of Ankara Training and Research Hospital approved the study protocol.

Participants had to meet the following eligibility criteria: (i) were aged 21-75 years, (ii) had RA or AS for at least one year, (iii) presented no major variations in drug therapy in the past six months before the trial, (iv) did not present severe disability that seriously compromised independence in activities of daily living and mobility.

The exclusion criteria were the following: (i) previous participation in rehabilitation in the past two years, (ii) major variations in drug therapy at any time during the trial, (iii) orthopedic surgery during the trial, (iv) the usage of an anti-TNF drug, (v) the usage of $>15 \mathrm{mg}$ prednisone daily, (vi) complete ankylosis of the spine for patients with AS, (vii) severe, disabling rheumatoid hand deformities.

At final analysis, 120 patients (66 females, 54 males; mean age $45.5 \pm 12.7$ years) were included in the perprotocol statistics (approximately 30 patients in each group). Those patients with RA according to the 1987 American College of Rheumatology (ACR) criteria were in the first group of participants. ${ }^{[33]}$ Patients with AS according to the modified New York criteria were in the second group of participants. ${ }^{[34]}$

\section{Interventions}

All patients received the same 10 minutes of instructions separately at their baseline and a five-visit reminder at 
the three-month interval checks over the 15 months of follow-ups.

\section{I- Inpatient rehabilitation model}

Sixty participants participated in 15 sessions of the physical therapy and rehabilitation program consisting of one daily session by four physical therapists with experience in RA and AS. They were treated in a hands-on, one-by-one manner.

The description of physical therapy by the World Confederation $^{[35]}$ was implemented and modified in order to reach agreed goals which may include manual handling; movement enhancement; physical, electro-therapeutic and mechanical agents; functional training; provision of assistive technologies; patientrelated instruction and counseling; documentation and coordination; and communication. Because of the involvement of the peripheral and axial joints, possible cardiopulmonary co-morbidities, and the different disease activity state of each patient, physical therapy and exercise prescription for rheumatic patients have been performed by physiatrists in Turkey. Physiotherapists, on the other hand, are responsible for the application of the prescribed physical therapy and exercise program medicolegally.

Therefore, each session of daily physical therapy and rehabilitation was provided by a physical therapist in this study. There were a limited number of systematic reviews for physical therapy with RA and AS. ${ }^{[2-4,19]}$ High-quality evidence for joint protection and patient education, intermediate-quality evidence for aerobic activities, dynamic strengthening and lowquality evidence for conventional physiotherapy such as paraffin wax baths, ultrasound, and transcutaneous nerve stimulator (TENS) for hands, comprehensive occupational therapy, and exercises were reported in an overview of systematic reviews, the Ottawa Panel, and clinical practice guidelines for the nonpharmacologic treatments of RA. ${ }^{[2-4]}$ However, there were no therapeutic ultrasound and TENS studies for rheumatoid knees despite their common usage in treatment.

Similarly, no study was found concerning hot pack, faradic current or ultrasound for spondylotic spine in other English literature for evidence-based analysis.

\section{Physical therapy modalities}

(a) Superficial heat: paraffin bath on the rheumatoid hands and hot packs on the spondylotic spine for 10 minutes, (b) Deep heat: ultrasound ( $0.5 \mathrm{watt} / \mathrm{cm}^{2} / 6$ mins) of rheumatoid knees and paravertebral spondylotic spine after the hot pack applications for 10 minutes,

(c) Electrotherapy: conventional TENS for rheumatoid knees and pulley faradic current for spondylotic paravertebral muscles for 10 minutes,

2. Occupational therapy ${ }^{[8]}$

(a) Joint protection, energy conservation, pacing for patients with RA,

(b) Activities of daily living training, joint protection (avoiding the same position for a long time, reducing the stress load on the spine, control of the sitting and head position), posture and positioning advice, energy conservation (regular resting, pace) for patients with AS.

\section{Exercises for patients with $R A^{[8]}$}

(a) Shoulder and back: active range of motion (AROM), rotation, mobilization.

(b) Elbow: rotation

(c) Wrist, finger: AROM

(d) Hip: hip hitches, abductor strengthening, rotation

(e) Knee: isometric quadriceps strengthening

(f) Ankle: mobilization

4. Exercises for patients with $A S^{[31]}$

(a) Posture

(b) Respiratory

(c) Endurance

(d) Shoulder and hip range of motion (ROM)

(e) Neck stretching and mobilization

(f) Trunk rotation

(g) Side bending

(h) Cat stretching

(i) Lower extremity stretching

Active range of motion exercises and isometric quadriceps strengthening were repeated 20 times in two sets daily. Mirror-reflected posture training and posture exercises were instructed. Respiratory exercises (deep breathing, diaphragmatic breathing, air-shifting and pursed lip breathing for 15 minutes) along with individualized walking endurance exercises were performed three times weekly. After three weeks of IRM, patients were discharged. 


\section{II- Home exercise model}

The sixty patients were instructed to perform the above-mentioned exercises. The patients were encouraged to perform them at home as two sets daily, with 20 repetitions per set, for three weeks. Respiratory and endurance exercises were also prescribed to the patients. There was no possibility for the HEM patients to ask questions of the PT or OT during the trial period. Every three months over the 15 months of treatment (a total of 5 visits), patients were asked about verbally whether or not they were adhering to their therapy.

Both groups received education and disease information including joint protection strategies, energy conservation and fatigue management, sleep hygiene training, management of flare, pain relief strategies, relaxation training along with exercise and physical activity recommendations.

\section{Outcomes}

Outcome measures of the AS group included changes in activity and functional capacity evaluated by an assessor blinded to the intervention using validated scores from the two Bath indices for AS. ${ }^{[3,37]}$ Similarly, outcome measures of the RA group were the Disease Activity Score 28 (DAS28) and Stanford Health Assessment Questionnaire (HAQ). ${ }^{[38,39]}$

Primary outcomes were the Stanford HAQ for patients with RA and the Bath Ankylosing Spondylitis Functional Index (BASFI) for patients with AS in this study. Secondary outcomes were composite variables including DAS28 for patients with RA and the Bath Ankylosing Spondylitis Disease Activity Index (BASDAI) for patients with AS.

The HAQ is a measuring status used to cover "functioning", It uses an ordinal score measure (range 0-3) to gauge difficulty in performing everyday activities during the previous week $^{[39]}$ and a 20 -item self-administered scale consisting of eight subscales (dressing and grooming, arising, eating, walking, hygiene, reach, grip, and "usual activities"). Each category contains at least two specific components. The BASFI, "functioning" measure of AS, is a mean of the set of 10 questions designed to determine the degree of functional limitation (range 0-10) in patients with AS. ${ }^{[37]}$

Composite disease activity measures such as DAS28 and BASDAI were used in this study. Disease activity score 28 is an index including 28 swollen joint counts (28-SJC) and 28 tender joint counts (28-TJC) in addition to patient global assessments of disease activity on a visual analog scale (VAS) and erythrocyte sedimentation rate (ESR). Predefined cut-off values for remission, low, and moderate disease activity are 2.6, 3.2 and 5.1, respectively. ${ }^{[40]}$ The BASDAI is includes a six-question patient survey utilizing a VAS to assess fatigue, axial and peripheral joint pain, tenderness, and severity and duration of morning stiffness. ${ }^{[36]}$ The sum of the first four questions plus the mean of morning stiffness questions were divided by five for the calculation of BASDAI.

Assessment intervals were every three months for disease activity indices and every 15 months for functional indices. Same-time indices were statistically analyzed at the baseline and at the end of the 15-month period. It was calculated that the number of patients included (22 in the intervention group and 21 in the control group) was the number necessary to detect a difference of $>0.6 \mathrm{U}$, with an alpha ( $\alpha$ ) risk of 0.05 and a beta $(\beta)$ risk of 0.30 .

\section{Randomization-sequence generation}

Randomly allocated patients were included in the study. Patients who fulfilled inclusion criteria were randomly selected for the IRM and HEM groups by two attending physiatrists. Another two physiatrists prescribed standardized PT, OT, and exercises programs for RA and AS patients according to the groups. Each patient was managed by one of the four female, experienced physical therapists who was on call when the patient was seen in the examination room. By design, each therapist treated approximately 30 participants during the two years of recruitment.

\section{Statistical analysis}

Statistical Package for Social Sciences (SPSS) 15.0 software (SPSS Inc., Chicago, Illinois, USA) was used for statistical analysis. Descriptive data was compared at the baseline for homogeneity in each patient group. Continuous data (e.g. DAS28, HAQ) was entered as means and standard deviations. NPar tests of MannWhitney $U$ and two sample Kolmogorov-Smirnov tests were used for drug characteristics. T-test paired sample statistics and correlations for outcomes were performed.

Multivariate tests of a general linear model were applied for "within-subjects" and "between-subjects" effects. In the general linear model analysis, the HAQ, DAS28, BASFI and BASDAI scores of baseline and follow-up were dependent variables of "within subjects" factors. Inpatient rehabilitation was a "between subjects" factor in this model. Tests of the null hypothesis that the observed covariance matrices 
of the dependent variables are equal across groups were designed for the HAQ, DAS28, BASFI and BASDAI. Bonferroni adjustments for multiple comparisons were based on estimated marginal means for pairwise comparisons of outcomes.

\section{Bias}

Similar baseline demographic and disease characteristics were also used to avoid selection bias. However, we couldn't provide blinding of patients and care providers because of the rehabilitation nature of this study (performance bias may occur). Intention-totreat analysis at follow-up was used to avoid attrition bias. All patients received intervention. Outcome assessors and data analysts were blinded to prevent detection bias. Effect size (0.2: small, 0.5: medium, 0.8: large) was calculated for statistically significant changing outcomes using the formula below: ${ }^{[1]}$

Effect size $=(\Delta$ treatment $-\Delta$ controls $) /$ pooled SD

Pooled SD $=\sqrt{ }[($ nt-1) $x$ SDt2 $+($ nc-1)x SDc2 $] /(n t+n c)$

\section{RESULTS}

\section{Flow}

A flow diagram of this study with the pool of potential patients showing that all were registered and randomized was shown in Figure 1. The online recorded, pre-planned study population was 115 patients with RA and 96 patients with AS.

\section{Descriptive data}

Of the 60 enrolled patients with RA (51 females, 9 males; mean age $51.8 \pm 11.7$ years; range 27 to 75 years; median age 54 years, and disease duration was $8.5 \pm 6.4$, median 7 years), 39 (65\%) were on combined DMARDs and $21(35 \%)$ were on mono-DMARD therapy. The Levene's Test for Homogeneity of Variances statistic showed homogeneity for age, disease duration, and baseline DAS28 and HAQ scores.

Of the 60 patients included with AS (16 females, 44 males; mean age $39.7 \pm 10.4$ years, median age 39 years, and disease duration was $8.7 \pm 7.8$, median 6 years), five (8.3\%) were on combined DMARDs and all patients were on NSAIDs therapy. The Levene's Test for Homogeneity of Variances statistic showed homogeneity for age, disease duration, and baseline BASDAI and BASFI scores. Baseline comparisons of statistical descriptive for IRM and HEM groups with RA and AS were similar, except for the HAQ and BASFI shown in Table 1.

Losses including dropout, surgery, drug changes and severe disability for each group were also shown in Figure 1. No significant adverse events were observed in either group. No additional DMARDs

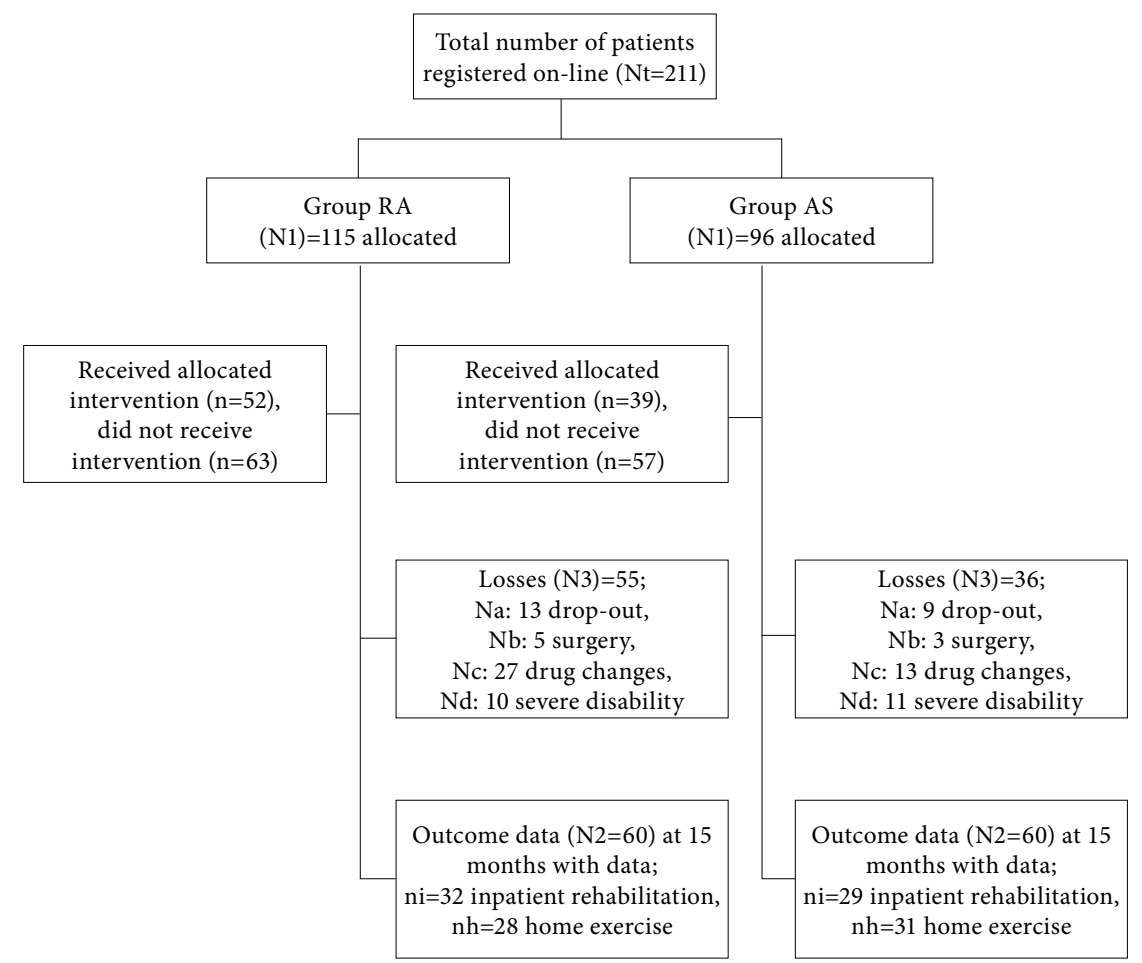

Figure 1. The flow diagram. RA: Rheumatoid arthritis; AS: Ankylosing spondylitis. 


\begin{tabular}{|c|c|c|c|c|c|c|c|}
\hline & \multicolumn{3}{|c|}{$\operatorname{IRM}(\mathrm{n}=32) \mathrm{RA}$} & \multicolumn{3}{|c|}{ HEM $(n=28)$ RA } & \multirow[t]{2}{*}{$p$} \\
\hline & $\mathrm{n}$ & $\%$ & Mean \pm SD & $\mathrm{n}$ & $\%$ & Mean \pm SD & \\
\hline Age (RA) & & & $54.2 \pm 11.1$ & & & $48 \pm 12.6$ & 0.05 \\
\hline \multicolumn{8}{|l|}{ Sex } \\
\hline Female & 28 & 87 & & 23 & 82.1 & & 0.6 \\
\hline Duration of RA & & & $9.9 \pm 8.2$ & & & $7.2 \pm 7.3$ & 0.2 \\
\hline Disease activity score 28 score & & & $5.4 \pm 1.1$ & & & $4.9 \pm 1.4$ & 0.2 \\
\hline HAQ score & & & $1.6 \pm 0.5$ & & & $1.1 \pm 0.5$ & $0.001^{*}$ \\
\hline MTX (years) & & & $3.9 \pm 1.5$ & & & $1.5 \pm 1.1$ & $0.02^{*}$ \\
\hline Combined DMARDs & 23 & 71.9 & & 16 & 57.1 & & $0.01^{\star}$ \\
\hline MTX+HCQ & 3 & 9.4 & & 7.1 & 2 & & 0.6 \\
\hline MTX+SSZ & 12 & 37.5 & & 8 & 28.6 & & 0.05 \\
\hline MTX+SSZ+HCQ & 5 & 15.6 & & 6 & 21.4 & & 0.5 \\
\hline $\mathrm{MTX}+\mathrm{LEF}+\mathrm{SSZ}$ & 2 & 6.3 & & 0 & 0 & & 0.4 \\
\hline $\mathrm{MTX}+\mathrm{SSZ}+\mathrm{HCQ}+\mathrm{LEF}$ & 1 & 3.1 & & 0 & 0 & & 0.9 \\
\hline NSAIDs (User) & 12 & 37.5 & & 14 & 50 & & 0.9 \\
\hline \multirow[t]{3}{*}{ Corticosteroids (User) } & 11 & 34.4 & & 7 & 25 & & 0.1 \\
\hline & \multicolumn{3}{|c|}{ IRM $(n=29)$ AS } & \multicolumn{3}{|c|}{$\operatorname{HEM}(n=31)$ AS } & \multirow[t]{2}{*}{$p$} \\
\hline & $\mathrm{n}$ & $\%$ & Mean \pm SD & $\mathrm{n}$ & $\%$ & Mean \pm SD & \\
\hline Age (AS) & & & $42.5 \pm 10.6$ & & & $37 \pm 9.6$ & 0.05 \\
\hline \multicolumn{8}{|l|}{ Sex } \\
\hline Male & 24 & 82.7 & & 20 & 64.5 & & $0.01^{\star}$ \\
\hline Duration of AS & & & $9.9 \pm 7.7$ & & & $7.4 \pm 7.7$ & 0.2 \\
\hline BASDAI score & & & $4.8 \pm 2.5$ & & & $3.9 \pm 2.3$ & 0.1 \\
\hline BASFI score & & & $5.0 \pm 2.9$ & & & $3.4 \pm 2.7$ & $0.04^{*}$ \\
\hline SSZ (years) & & & $5.4 \pm 4.6$ & & & $5.1 \pm 5.4$ & 0.8 \\
\hline Combined DMARDs & 4 & 13.8 & & 1 & 3.2 & & 0.05 \\
\hline NSAIDs (User) & 24 & 83.8 & & 25 & 80.6 & & 0.8 \\
\hline
\end{tabular}

were added to the previous pharmacotherapy. None of the patients used anti-TNF drugs. The maximum dose of methotrexate was $25 \mathrm{mg}$ weekly, and the maximum dose of prednisone was $15 \mathrm{mg}$ daily in this study. All patients were taking NSAIDs, on an individual, as-needed basis.

\section{Changes in the outcome measures}

When adjusting for significant differences at baseline between the two groups, there were significantly larger improvements in the HAQ and DAS28 scores of RA patients among the patients in the inpatient rehabilitation group compared with the home exercise group.

The Stanford HAQ and DAS28 for RA and BASFI and BASDAI for AS were dependent variables of "within-subjects" factors in general linear model analysis. After the Bonferroni adjustment of multiple comparisons, multivariate test results were shown in
Table 2. Both the improvement of DAS28 $(\mathrm{p}=0.001)$ and HAQ scores $(p=0.001)$ were better in the IRM group than in the HEM group ( $\mathrm{p}=0.001)$. In contrast, changes in BASDAI $(\mathrm{p}=0.07)$ and BASFI $(\mathrm{p}=0.08)$ were similar in both IRM and HEM groups.

Calculated effect sizes of IRM were 0.2 (small) for DAS28 and 0.6 (medium) for HAQ.

\section{DISCUSSION}

We found that compared to home exercise, comprehensive inpatient rehabilitation was effective for function and disease activity in patients with RA but had no effect on those with AS. This situation might be related to the difference in pharmacologic treatments. Most of our patients with RA were on combined DMARDs therapy, but none of the patients with AS were on anti-TNF therapy in our sample. Patients were followed-up regularly at three-month intervals for 12 months. Functional measures were 


\begin{tabular}{|c|c|c|c|c|c|c|}
\hline & \multicolumn{2}{|c|}{$\operatorname{IRM}(n=32) \mathrm{RA}$} & \multicolumn{2}{|c|}{ HEM $(n=28)$ RA } & \multicolumn{2}{|c|}{ Multivariate } \\
\hline & Mean \pm SD & $p$ & Mean \pm SD & $p$ & $\mathrm{~F}$ & $p$ \\
\hline DAS28 baseline & $5.4 \pm 1.1$ & & $4.9 \pm 1.4$ & & & \\
\hline DAS28 follow-up & $4.1 \pm 1.3$ & & $4.1 \pm 1.2$ & & & \\
\hline Pairwise compare & & $0.001^{*}$ & & $0.001^{\star}$ & 34.3 & $0.001^{\star}$ \\
\hline HAQ baseline & $1.6 \pm 0.5$ & & $1.1 \pm 0.5$ & & & \\
\hline HAQ follow-up & $1 \pm 0.7$ & & $0.7 \pm 0.6$ & & & \\
\hline \multirow[t]{3}{*}{ Pairwise compare } & & $0.001^{*}$ & & $0.001^{*}$ & 46.1 & $0.001^{\star}$ \\
\hline & \multicolumn{2}{|c|}{ IRM $(n=29)$ AS } & \multicolumn{2}{|c|}{$\operatorname{HEM}(n=31)$ AS } & \multicolumn{2}{|c|}{ Multivariate } \\
\hline & Mean \pm SD & $p$ & Mean \pm SD & $p$ & $\mathrm{~F}$ & $p$ \\
\hline BASDAI baseline & $4.8 \pm 2.5$ & & $3.9 \pm 2.3$ & & & \\
\hline BASDAI follow-up & $4 \pm 3.6$ & & $2.5 \pm 2.4$ & & & \\
\hline Pairwise compare & & 0.07 & & 0.07 & 3.6 & 0.07 \\
\hline BASFI baseline & $5.0 \pm 2.9$ & & $3.4 \pm 2.7$ & & & \\
\hline BASFI follow-up & $4.2 \pm 3.3$ & & $2.7 \pm 3.1$ & & & \\
\hline Pairwise compare & & 0.08 & & 0.08 & 3.1 & 0.08 \\
\hline
\end{tabular}

repeated yearly; therefore, the same-time baseline and 12-month results were analyzed.

In our study, both the rehabilitation and home exercise groups received education and disease information including joint protection strategies, energy conservation and fatigue management, sleep hygiene training, management of flare, pain relief strategies, relaxation training, assistive devices, home exercise program, and physical activity recommendations (defined as moderately intensive activity most days of the week) in addition to participation in physical activity in everyd ay life. ${ }^{[18]}$ The rehabilitation group also received o physical therapy modalities (thermotherapy, electrotherapy).

Because of the additive effects of different modalities, comprehensive and multidisciplinary rehabilitation programs have been routinely advocated. Such programs are aimed at improving disease activity and physical and psychosocial functioning with the ultimate goal of assisting patients to achieve and maintain maximal personal independence. In our study, more disabled cases needed inpatient rehabilitation. Therefore, the inpatient group had higher baseline scores on the HAQ and BASFI compared to the HEM group.

The complementary role of rehabilitation is supported by a number of systematic reviews and umbrella reviews for the management of RA ${ }^{[3,10,13,16,18]}$ and AS. ${ }^{[18,19,21,31,41]}$ International guidelines, including the ones developed by the ACR guidelines on RA, ${ }^{[1]}$ and the Assessment of Spondylo Arthritis International Society (ASAS) and the European League Against Rheumatism (EULAR) recommendations on $\mathrm{AS}^{[42]}$ also endorse the use of non-pharmacological interventions as an adjunct.

These guidelines originated from evidencebased medicine and there were some differences and similarities between RA and AS. ${ }^{[18]}$

While aerobic activities, dynamic strengthening, and patient education concerned intermediate evidence level, the use of splints and assistive devices, balneotherapy and spa therapy, and conventional physiotherapy had a low evidence level in RA. ${ }^{[2]}$ The Ottawa Panel also recommends the use of physical therapy (low-level laser therapy, therapeutic ultrasound, thermotherapy, electrical stimulation, and TENS) for the management of RA. ${ }^{[4]}$ After this panel, there was high-quality evidence for the beneficial effects of joint protection and patient education; moderate-quality evidence for beneficial effects of low-level laser therapy; and low-quality evidence for thermotherapy, ultrasound, electrotherapy, acupuncture, balneotherapy, splints, diet and exercises in an overview of systematic reviews. ${ }^{[3]}$ We used most of these modalities in a combined physical therapy and rehabilitation approach. Dynamic exercises are the cornerstone of the non-pharmacologic treatment 
in this study. Electro-physical modalities involving the use of thermal, electrical, and sound energy have been used to generate therapeutic physiological effects with the aim of reducing pain, preparing exercises or restoring function in the rehabilitation practice. Unfortunately, there is no universal model of rehabilitation for patients with RA. The Finnish statutory inpatient rehabilitation system, as an example, had no positive impact on either functional (HAQ) or work capacity during the first few years for patients with recent-onset RA in the Finnish rheumatoid arthritis combination (Fin-RACo) trial with a five-year follow-up. ${ }^{[7]}$ Baseline socioeconomic demographics were different in this longterm retrospective trial. In contrast, our patients with chronic RA showed similar characteristics with significant improvement in function and disease activity after 15-months of follow-up.

Compared to RA, there are relatively few controlled non-pharmacological intervention studies in AS. A Cochrane review showed that supervised group physiotherapy had moderate quality of evidence; home exercise had low quality of evidence on mobility and physical function in AS ${ }^{\left[{ }^{[19]}\right.}$ In small controlled studies, it was found that group physiotherapy (inpatient) was not better than home exercise in pain, ${ }^{[43,44]}$ morning stiffness, ${ }^{[44]}$ BASFI, ${ }^{[44]}$ and spinal mobility, ${ }^{[43,44]}$ except for the modified Schoeber test ${ }^{[44]}$ in small controlled studies for three week inpatient hydrotherapy + exercise $^{[45]}$ and six-week inpatient exercise ${ }^{[41]}$ interventions over six months of follow-up of small samples. Disease activity was not evaluated in these studies. Similarly, we couldn't find any difference of BASFI and BASDAI between inpatient rehabilitation and home exercise in our sample. It might depend on pharmacologic treatments having no effect on the disease process of AS. None of our patients used anti-TNF drugs in this study. Lubrano et al. ${ }^{[30]}$ found that an intensive rehabilitation program combined with etanercept was significantly better than rehabilitation alone in terms of BASFI, the Revised Leeds Disability Questionnaire, spinal mobility and 6-min walking test. Elyan and Khan ${ }^{[31]}$ recommended instructions on proper posture training and a home exercise program of stretching, spinal extension and deep breathing exercises twice daily for every patient with AS and encouraged them to perform water exercises if they could. They also recommended formal physical therapy, and in the most severe cases, inpatient rehabilitation may be of benefit to select patients with AS. In addition, patients at risk for cardiovascular disease should be carefully evaluated to determine the safety of an exercise program.

In comparison with regular outpatient care, inpatient comprehensive multidisciplinary team care programs were more effective, but slightly more expensive. ${ }^{[45]}$ However, we don't have cost of care studies about inpatient care compared to home exercise in Turkey. From the literature we know that inpatient care is expensive; therefore, home exercises could be beneficial, but not sufficient enough for some patients. Currently, inpatient care is reserved for patients who have the most advanced rheumatic disease with the most functional impairment. The illness must be sufficiently severe to require daily monitoring by physicians and healthcare professionals. Actually, inpatient rehabilitation is not defined by the diagnostic related groups (DRG) system in developed countries, but it has also responded to the trend of reduced inpatient days. ${ }^{[46]}$ Medicare requires that patients with rheumatic disease have reductions in activities of daily living and mobility that have not responded to outpatient treatment.

Patients' functioning is a central aspect of the rheumatic disease according to the International Classification of Functioning, Disability and Health (ICF) core sets for RA and AS. ${ }^{[47]}$ We found that our inpatient rehabilitation model is useful for patients' functioning in patients with RA on DMARDs therapy. However, inpatient rehabilitation had no impact on function in patients with AS using NSAIDs therapy. Inpatient rehabilitation programs should be recommended to disabled patients with RA while participating in effective pharmacologic therapy. Because little is known about the optimal model(s) for providing rehabilitative care for patients with RA and AS, more research will be needed to guide clinicians' decisions in using both inpatient and outpatient rheumatologic rehabilitation programs. Further welldesigned clinical studies are warranted with respect to several rehabilitation interventions where evidence is falling short.

\section{Declaration of conflicting interests}

The authors declared no conflicts of interest with respect to the authorship and/or publication of this article.

\section{Funding}

The authors received no financial support for the research and/or authorship of this article. 


\section{REFERENCES}

1. American College of Rheumatology Subcommittee on Rheumatoid Arthritis Guidelines. Guidelines for the management of rheumatoid arthritis: 2002 Update. Arthritis Rheum 2002;46:328-46.

2. Forestier R, André-Vert J, Guillez P, Coudeyre E, Lefevre-Colau MM, Mayoux-Benhamou MA. Nondrug treatment (excluding surgery) in rheumatoid arthritis: clinical practice guidelines. Joint Bone Spine 2009;76:691-8.

3. Christie A, Jamtvedt G, Dahm KT, Moe RH, Haavardsholm EA, Hagen KB. Effectiveness of nonpharmacological and nonsurgical interventions for patients with rheumatoid arthritis: an overview of systematic reviews. Phys Ther 2007;87:1697-715.

4. Ottawa Panel. Ottawa Panel Evidence-Based Clinical Practice Guidelines for Electrotherapy and Thermotherapy Interventions in the Management of Rheumatoid Arthritis in Adults. Phys Ther 2004;84:1016-43.

5. Flint-Wagner HG, Lisse J, Lohman TG, Going SB, Guido T, Cussler E, et al. Assessment of a sixteen-week training program on strength, pain, and function in rheumatoid arthritis patients. J Clin Rheumatol 2009;15:165-71.

6. Baillet A, Payraud E, Niderprim VA, Nissen MJ, Allenet B, François $\mathrm{P}$, et al. A dynamic exercise programme to improve patients' disability in rheumatoid arthritis: a prospective randomized controlled trial. Rheumatology (Oxford) 2009;48:410-5.

7. Puolakka K, Kautiainen H, Möttönen T, Hannonen P, Pohjolainen T, Korpela M, et al. Cost of Finnish statutory inpatient rehabilitation and its impact on functional and work capacity of patients with early rheumatoid arthritis: experience from the FIN-RACo trial. Scand J Rheumatol 2007;36:270-7.

8. Masiero S, Boniolo A, Wassermann L, Machiedo $\mathrm{H}$, Volante D, Punzi L. Effects of an educational-behavioral joint protection program on people with moderate to severe rheumatoid arthritis: a randomized controlled trial. Clin Rheumatol 2007;26:2043-50.

9. Macedo AM, Oakley SP, Panayi GS, Kirkham BW. Functional and work outcomes improve in patients with rheumatoid arthritis who receive targeted, comprehensive occupational therapy. Arthritis Rheum 2009;61:1522-30.

10. Vliet Vlieland TP. Multidisciplinary team care and outcomes in rheumatoid arthritis. Curr Opin Rheumatol 2004;16:153-6.

11. Vliet Vlieland TP, Breedveld FC, Hazes JM. The twoyear follow-up of a randomized comparison of in-patient multidisciplinary team care and routine out-patient care for active rheumatoid arthritis. Br J Rheumatol 1997; 36:82-5.

12. de Jong Z, Munneke M, Zwinderman AH, Kroon HM, Jansen A, Ronday $\mathrm{KH}$, et al. Is a long-term high-intensity exercise program effective and safe in patients with rheumatoid arthritis? Results of a randomized controlled trial. Arthritis Rheum 2003;48:2415-24.
13. Hurkmans E, van der Giesen FJ, Vliet Vlieland TP, Schoones J, Van den Ende EC. Dynamic exercise programs (aerobic capacity and/or muscle strength training) in patients with rheumatoid arthritis. Cochrane Database Syst Rev 2009;CD006853.

14. Neuberger GB, Aaronson LS, Gajewski B, Embretson SE, Cagle PE, Loudon JK, et al. Predictors of exercise and effects of exercise on symptoms, function, aerobic fitness, and disease outcomes of rheumatoid arthritis. Arthritis Rheum 2007;57:943-52.

15. Häkkinen A, Hannonen P, Nyman K, Lyyski T, Häkkinen K. Effects of concurrent strength and endurance training in women with early or longstanding rheumatoid arthritis: comparison with healthy subjects. Arthritis Rheum 2003;49:789-97.

16. Robinson V, Brosseau L, Casimiro L, Judd M, Shea B, Wells G, et al. Thermotherapy for treating rheumatoid arthritis. Cochrane Database Syst Rev 2002;CD002826.

17. Abourazzak F, El Mansouri L, Huchet D, Lozac'hmeur R, Hajjaj-Hassouni N, Ingels A, et al. Longterm effects of therapeutic education for patients with rheumatoid arthritis. Joint Bone Spine 2009;76:648-53.

18. Vliet Vlieland TP, Li LC. Rehabilitation in rheumatoid arthritis and ankylosing spondylitis: differences and similarities. Clin Exp Rheumatol 2009;27:S171-8.

19. Dagfinrud H, Kvien TK, Hagen KB. Physiotherapy interventions for ankylosing spondylitis. Cochrane Database Syst Rev 2008;CD002822.

20. Hammond A. What is the role of the occupational therapist? Best Pract Res Clin Rheumatol 2004;18:491505.

21. Dougados M, Dijkmans B, Khan M, Maksymowych W, van der Linden S, Brandt J. Conventional treatments for ankylosing spondylitis. Ann Rheum Dis 2002;61 Suppl 3:iii40-50.

22. Sweeney S, Taylor G, Calin A. The effect of a home based exercise intervention package on outcome in ankylosing spondylitis: a randomized controlled trial. J Rheumatol 2002;29:763-6.

23. Viitanen JV, Heikkilä S. Functional changes in patients with spondylarthropathy. A controlled trial of the effects of short-term rehabilitation and 3-year follow-up. Rheumatol Int 2001;20:211-4.

24. Spadaro A, De Luca T, Massimiani MP, Ceccarelli F, Riccieri V, Valesini G. Occupational therapy in ankylosing spondylitis: Short-term prospective study in patients treated with anti-TNF-alpha drugs. Joint Bone Spine 2008;75:29-33.

25. Durmus D, Alayli G, Cil E, Canturk F. Effects of a home-based exercise program on quality of life, fatigue, and depression in patients with ankylosing spondylitis. Rheumatol Int 2009;29:673-7.

26. Durmuş D, Alayli G, Uzun O, Tander B, Cantürk F, Bek Y, et al. Effects of two exercise interventions on pulmonary functions in the patients with ankylosing spondylitis. Joint Bone Spine 2009;76:150-5. 
27. Widberg K, Karimi H, Hafström I. Self- and manual mobilization improves spine mobility in men with ankylosing spondylitis-a randomized study. Clin Rehabil 2009;23:599-608.

28. Karapolat H, Eyigor S, Zoghi M, Akkoc Y, Kirazli Y, Keser G. Are swimming or aerobic exercise better than conventional exercise in ankylosing spondylitis patients? A randomized controlled study. Eur J Phys Rehabil Med 2009;45:449-57.

29. Lubrano E, D’Angelo S, Parsons WJ, Corbi G, Ferrara N, Rengo $\mathrm{F}$, et al. Effectiveness of rehabilitation in active ankylosing spondylitis assessed by the ASAS response criteria. Rheumatology (Oxford) 2007;46:1672-5.

30. Lubrano E, D’Angelo S, Parsons WJ, Serino F, Tanzillo AT, Olivieri I, et al. Effects of a combination treatment of an intensive rehabilitation program and etanercept in patients with ankylosing spondylitis: a pilot study. J Rheumatol 2006;33:2029-34.

31. Elyan M, Khan MA. Does physical therapy still have a place in the treatment of ankylosing spondylitis? Curr Opin Rheumatol 2008;20:282-6.

32. Boutron I, Moher D, Altman DG, Schulz KF, Ravaud P; CONSORT Group. Extending the CONSORT statement to randomized trials of nonpharmacologic treatment: explanation and elaboration. Ann Intern Med 2008;148:295-309.

33. Arnett FC, Edworthy SM, Bloch DA, McShane DJ, Fries JF, Cooper NS, et al. The American Rheumatism Association 1987 revised criteria for the classification of rheumatoid arthritis. Arthritis Rheum 1988;31:315-24.

34. van der Linden S, Valkenburg HA, Cats A. Evaluation of diagnostic criteria for ankylosing spondylitis. A proposal for modification of the New York criteria. Arthritis Rheum 1984;27:361-8.

35. Available from: http://www.wcpt.org/node/29599

36. Garrett S, Jenkinson T, Kennedy LG, Whitelock H, Gaisford P, Calin A. A new approach to defining disease status in ankylosing spondylitis: the Bath Ankylosing Spondylitis Disease Activity Index. J Rheumatol 1994;21:2286-91.

37. Calin A, Garrett S, Whitelock H, Kennedy LG, O’Hea J, Mallorie P, et al. A new approach to defining functional ability in ankylosing spondylitis: the development of the Bath Ankylosing Spondylitis Functional Index. J Rheumatol 1994;21:2281-5.
38. Prevoo ML, van 't Hof MA, Kuper $H H$, van Leeuwen MA, van de Putte LB, van Riel PL. Modified disease activity scores that include twenty-eight-joint counts. Development and validation in a prospective longitudinal study of patients with rheumatoid arthritis. Arthritis Rheum 1995;38:44-8.

39. Küçükdeveci AA, Sahin H, Ataman S, Griffiths B, Tennant A. Issues in cross-cultural validity: example from the adaptation, reliability, and validity testing of a Turkish version of the Stanford Health Assessment Questionnaire. Arthritis Rheum 2004;51:14-9.

40. van GestelAM, Prevoo ML, van'tHofMA, van RijswijkMH, van de Putte LB, van Riel PL. Development and validation of the European League Against Rheumatism response criteria for rheumatoid arthritis. Comparison with the preliminary American College of Rheumatology and the World Health Organization/International League Against Rheumatism Criteria. Arthritis Rheum 1996;39:34-40.

41. Nghiem FT, Donohue JP. Rehabilitation in ankylosing spondylitis. Curr Opin Rheumatol 2008;20:203-7.

42. Zochling J, van der Heijde D, Dougados M, Braun J. Current evidence for the management of ankylosing spondylitis: a systematic literature review for the ASAS/ EULAR management recommendations in ankylosing spondylitis. Ann Rheum Dis 2006;65:423-32.

43. Helliwell P, Abbott CA, Chamberlain MA. A randomized trial of three different physiotherapy regimes in ankylosing spondylitis. Physiotherapy 1996;82:85-90.

44. Analay Y, Ozcan E, Karan A, Diracoglu D, Aydin R. The effectiveness of intensive group exercise on patients with ankylosing spondylitis. Clin Rehabil 2003;17:631-6.

45. Vliet Vlieland TP. Rehabilitation of people with rheumatoid arthritis. Best Pract Res Clin Rheumatol 2003;17:847-61.

46. Beardmore TD. Rehabilitation of patients with rheumatic diseases. In: Klippel JH, Stone JH, Crofford LJ, White PH, editors. Primer on the rheumatic diseases. 13th ed. New York: Springer; 2008. p. 599-608.

47. Rauch A, Cieza A, Boonen A, Ewert T, Stucki G. Identification of similarities and differences in functioning in persons with rheumatoid arthritis and ankylosing spondylitis using the International Classification of Functioning, Disability and Health (ICF). Clin Exp Rheumatol 2009;27:S92-101. 